\title{
Climate Change Mitigation in Cities: Challenges and Opportunities
}

\author{
Rajasekhar Balasubramanian \\ Department of Civil and Environmental Engineering \\ National University of Singapore \\ Singapore 117576 \\ E-mail: ceerbala@nus.edu.sg
}

\begin{abstract}
Urban growth is taking place on an unprecedented scale globally, and its adverse impacts on the environment and society are evident. These impacts are mainly caused by rapid population growth, and a net total growth of consumption of natural resources, combined with rapid industrialization, urbanization, mobilization, globalization, agricultural intensification, and excessive consumption driven lifestyles. One of the major environmental issues in cities worldwide is to mitigate climate change. In 2015, world leaders agreed to keep the increase in global average temperature to less than $2{ }^{\circ} \mathrm{C}$, and ideally 1.5 ${ }^{\circ} \mathrm{C}$, above preindustrial levels by the end of the century. Achieving this target requires strong commitments towards decarbonization across the electricity generation, urban transport, industrial, manufacturing and residential sectors because many human activities that address our basic needs, development, and well-being are sources of greenhouse gases. This keynote lecture will provide evidence-based insights relevant to the design of urban decarbonization targets and policies.
\end{abstract}

